\title{
Viewpoint: Turning streets into housing
}

\author{
Adam Millard-Ball \\ University of California, Los Angeles \\ adammb@ucla.edu
}

Abstract: I argue that wide residential streets in US cities are both a contributor to homelessness and a potential strategy to provide more affordable housing. In residential neighborhoods, subdivision ordinances typically set binding standards for street width, far in excess of what is economically optimal or what private developers and residents would

\section{Article history:}

Received: February 17, 2021

Accepted: June 13, 2021

Available online: October 4, 2021 likely prefer. These street width standards are one contributor to high housing costs and supply restrictions, which exacerbate the housing affordability crisis in high-cost cities. Planning for autonomous vehicles highlights the overprovision of streets in urban areas. Because they can evade municipal anti-camping restrictions that restrict the use of streets by unhoused people, autonomous camper vans have the ability to blur the distinction between land for housing and land for streets. I propose two strategies through which excess street space can accommodate housing in a formalized way. First, cities could permit camper van parking on the rightof-way, analogous to liveaboard canal boats that provide housing options in some UK cities. Second, extending private residential lots into the right-of-way would create space for front-yard accessory dwelling units.

\section{Introduction}

"Living on the streets" is synonymous with homelessness. While unhoused people use many different strategies for shelter, from couch surfing to formalized shelter accommodation, the images of street sleepers is particularly visceral. The number of people living on the streets is also a visible reflection of the scale of the housing and homelessness crisis in the United States (the focus of this paper) and beyond. Less obvious to the passer-by are the many people who live in cars, camper vans (recreational vehicles or RVs), and other vehicles, often parking on the street. ${ }^{1}$

At the same time, the number of people living on the streets reflects the sheer amount of space that is available on rights-of-way, whether on sidewalks, in medians, in parking spaces, or at the side of freeways. Between $13 \%$ and $30 \%$ of land in US cities may be devoted to street rights-of-way (Manvel, 1968, summarized in Meyer \& Gómez-Ibáńez, 1981, p. 181; see also Manville \& Shoup, 2005). In

\footnotetext{
${ }^{1}$ The most comprehensive source of homelessness data in the US, the federal Annual Housing Assessment Report (HUD, 2020), provides a breakdown by people in sheltered (e.g., in emergency shelters) and unsheltered (e.g., in vehicles, tents, or doorways) locations. It does not disaggregate the "unsheltered" category further to distinguish between vehicles and other unsheltered locations. However, counts conducted in individual cities such as Berkeley, CA and Seattle, WA sometimes find that more than half of unsheltered people are living in vehicles (e.g., All Home, 2020; Dinkelspiel, 2019).
}

Copyright 2021 Adam Millard-Ball

http://dx.doi.org/10.5198/jtlu.2021.2020

ISSN: 1938-7849 | Licensed under the Creative Commons Attribution - Noncommercial License 4.0

The Journal of Transport and Land Use is the official journal of the World Society for Transport and Land Use (WSTLUR) and is published and sponsored by the University of Minnesota Center for Transportation Studies. This paper is also published with additional sponsorship from WSTLUR. 
the urbanized portion of the largest US counties, the average residential street is 55 feet $(17 \mathrm{~m})$ wide, ${ }^{2}$ far exceeding the width needed for transportation functions alone (Millard-Ball, 2021).

The use of streets by unhoused people is normally seen as a social problem. Social services agencies often aim to help people "get off the streets," while cities adopt anti-camping and similar ordinances to prevent overnight sleeping in tents or vehicles by unhoused people. In this Viewpoint, in contrast, I argue that there is no inherent problem with the use of streets by unhoused people in this way. Rather, the problem is the lack of services and support, and the criminalization of such behavior. In short, I argue that cities should not seek to evict unhoused people from the streets, but rather find ways to turn those streets into adequate housing. Streets provide the largest reservoir of public land in most cities, and much of this land can and should be used to house, or at least shelter, unhoused people.

In this Viewpoint, I first discuss the economic as well as the social imperative for turning streets into housing. The marginal value of street rights-of-way is effectively zero in much of the US, implying that land for streets would be better put to other uses. I then suggest that if and when autonomous vehicles become widely available, the imperative may become a practical one as well. Anti-camping ordinances become hard to enforce when a car or camper van can slowly cruise or periodically reposition itself throughout the night. The final section of this Viewpoint discusses the practicality of turning streets into housing. I sketch out two potential pathways for established neighborhoods: dedicating parking for camper vans, and widening front setbacks into the street to create space for accessory dwelling units.

\section{Street design and the housing affordability crisis}

Over the past century, decisions over the dimensions of streets have become the domain of engineers (Norton, 2008). Street rights-of-way have been laid out according to the prescriptions of subdivision codes, which often incorporate by reference the standards in city or county engineering manuals. The influence of subdivision codes can be seen in the distributions of widths of residential rights-of-way. Rather than a smooth distribution that would likely result from the decisions of different developers, the right-of-way widths are heavily modal, or peaked, reflecting the prescriptions of local ordinances (Millard-Ball, 2021). In Maricopa County, Arizona, for example, nearly two-thirds of urban, residential rights-of-way, when rounded to the nearest foot, are precisely 50 feet $(15 \mathrm{~m})$ wide (Millard-Ball, 2021) the same width specified in local standards such as those of the City of Phoenix. ${ }^{3}$

The fact that few if any developers build wider-than-required rights-of-way is compelling evidence that subdivision codes are binding (Millard-Ball, 2021). That is, the codes force developers to construct rights-of-way that are wider than they would have chosen otherwise. In the absence of regulation, developers might be expected to respond to the interests of the initial residents. If those first-purchasers prefer houses on wide boulevards, and are willing to pay for wider streets, developers would presumably build accordingly, to the extent that they are permitted by local subdivision, zoning, and building codes.

Street-width standards might have a compelling justification if there were broad social benefits to wider streets - for example, in alleviating citywide traffic congestion or allowing for protected bicycle lanes for those traversing the neighborhood. However, in a typical subdivision with little or no through traffic, practically all the benefits of streets accrue to the residents themselves. To the extent that a wider right-of-way provides more space for on-street parking or landscaping, enables quicker access by fire-

\footnotetext{
${ }^{2}$ In the United States, roadway design standards are invariably specified in feet. I therefore use Imperial units throughout this paper.

${ }^{3}$ The City of Phoenix subdivision codes incorporates the city's Street Planning and Design Guidelines by reference. Right-of-way widths are specified in Table 3.1 and individual cross sections. See https://www.phoenix.gov/streetssite/Documents/d 039263. pdf
} 
fighters, or reduces traffic congestion, residents of that neighborhood are the primary if not exclusive beneficiaries.

On-street parking provides an illustrative example. In most suburban US neighborhoods, the marginal value of an on-street parking space is zero. Spaces are almost always available, and a resident advertising off-street parking for rent (perhaps in their garage or driveway) could expect few if any takers. This does not mean that the close substitute of on-street parking has no value, but rather than it is provided in such large quantities that demand is fully saturated, even at a price of zero. Through a back-of-theenvelope calculation, Guo and Schloeter (2013) suggest that there are more on-street spaces in suburban neighborhoods than passenger vehicles in the US. Residents would presumably prefer to have some of that excess land for streets repurposed for larger yards, or to have realized the cost savings from building narrower streets in the first place.

One measure of the opportunity cost of wide streets is the value of the land underneath them. Take a typical 50' wide suburban lot, on a right-of-way that is 50' wide. The house will have 1,250 square feet (116 square meters) of right-of-way along its frontage, measured from the lot line to the street centerline. Reducing that right-of-way to the functional minimum of $16^{\prime}$ (or 8' on each side) brings the right-ofway from 1,250 sq. ft. to 400 sq. $\mathrm{ft}$. In a city such as San Jose, California, where raw land values exceed $\$ 2$ million per acre (Davis, Larson, Oliner, \& Shui, 2020), such a width reduction brings the value of that right-of-way from over $\$ 57,000$ to about $\$ 18,000$ - a reduction of about $\$ 39,000$ per unit. In most cities, of course, land values are not as stratospheric, but the physical space requirements of wide streets are the same. And while a residential street just 16 feet $(5 \mathrm{~m})$ wide (including space for pedestrians) might seem unconscionably narrow in US terms, it would be unremarkable in many other parts of the world. In Paris, Seoul, Osaka, and Milan, streets in recent development are on average less than 20 feet ( $7 \mathrm{~m}$ ) wide (Angel et al., 2016). A shared surface of 16 feet can accommodate slow-moving bidirectional traffic as well as pedestrians and cyclists (Millard-Ball, 2021).

Overly wide streets have many consequences, such as traffic safety, urban heat, and stormwater runoff. Often, these negative effects can be mitigated by design — for example, through narrowing traffic lanes, adding bioswales or street trees, and adding bicycle lanes (NACTO, 2013). But these design interventions rarely change the overall width of the right of way, and thus do not change the cost of the land.

The impact of wide streets on housing affordability can occur through two main channels. First is the development cost: for a given number of housing units, narrower streets mean that either less land needs to be purchased by the subdivision developer, or that the cost of land purchase can be apportioned among a larger number of units. Infrastructure costs will also be lower on a per-unit basis, given that less asphalt needs to be poured. The extent to which these costs savings are captured by the land owner or developer or result in lower purchase prices depends on the supply and demand elasticities in the local land and housing markets, and on the market power of the various players.

The second channel is through supply: less land for streets means that more land can be developed for housing. In the example above, assuming 50 by 1,000 foot lots, reducing street widths from 50 feet to 16 feet would enable densities to rise from roughly seven to eight units per acre-still low, but a substantial $14 \%$ increase. ${ }^{4}$ Again, the impact on prices from an increase in aggregate supply will depend on the characteristics of the local housing market, but a large body of research suggests that regulatory constraints that reduce housing production have a measurable impact on prices (Been, Ellen, \& O'Regan, 2019; Glaeser \& Gyourko, 2018; Lin \& Wachter, 2020).

Incidentally, these two channels operate in a similar way to other regulatory reforms, such as the

4 This simplified calculation ignores corner lots and intersections. With a $50 \times 1000$ foot lot and a 50-foot wide right-of-way $(1,250 \mathrm{sq} \mathrm{ft}$ per lot $), 43,560 /(5000+1250)=7$ units per acre are possible. With a 16 -foot right-of-way (400 sq ft per lot), $43,560 /(5000+400)=8$ units per acre are possible. 
removal of minimum parking requirements, that reduce the cost and land consumption of new development. In the case of parking requirements, less off-street parking reduces construction costs, with the savings distributed among landowners, developers, and first-purchasers; and allows expansion of the housing supply. Seattle's parking reforms, for example, resulted in the construction of an estimated 18,000 fewer spaces with associated savings of $\$ 537$ million (Gabbe, Pierce, \& Glowers, 2020).

In summary, subdivision standards are one contributor to the growing housing affordability crisis, particularly in coastal California and other places where underlying land values are high. By mandating excessively wide rights-of-way, the standards increase the cost and reduce the supply of housing construction. To the extent that homelessness is exacerbated by a lack of affordable housing (e.g., Quigley \& Raphael, 2001), a direct line can be traced from wide streets to growing number of people who make those same streets their home.

\section{$3 \quad$ Streets as housing}

The strong likelihood that US cities devote too much land to streets and too little to housing might go unnoticed were it not possible for people to turn streets into housing, albeit in an unauthorized manner. Tents, cardboard boxes, and other makeshift forms of shelter are a visceral symbol. But while precise counts are scarce, many people live in camper vans parked on the street (Figure 1), and even in regular cars (Wehman-Brown, 2016). Homeless counts in San Francisco captured nearly 1,800 people living in their vehicles in 2019 (Ho, 2019). In King County, Washington, the figure is more than 2,500 (All Home, 2020).

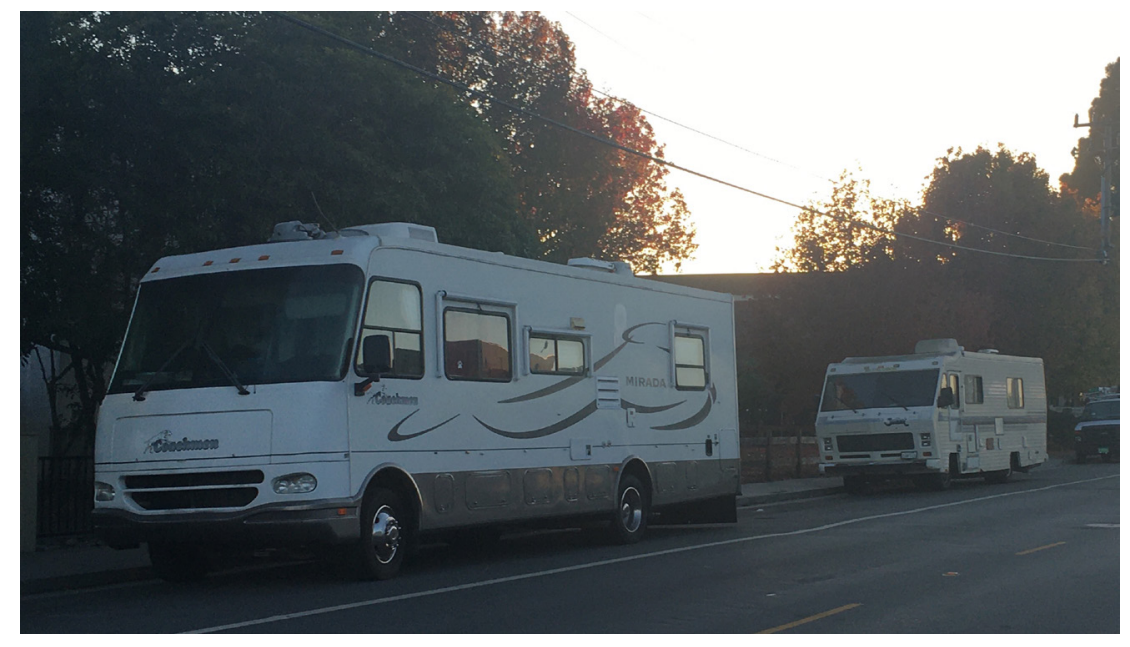

Figure 1. Camper van living, Santa Cruz, California Photo: Author

Vehicle residents may or may not consider themselves homeless and exist on a continuum of housing options from the temporary to permanent. Wakin $(2008,2014)$ offers detailed ethnographic accounts highlighting the challenges but also the benefits of RV living — safety, privacy, and autonomyover other options for shelter that may be available. "The Lady in the Van," an essay and later a movie starring Dame Maggie Smith in the title role, provides another portrayal, recounting the true story of a van resident, Miss Shepherd. She initially parks on a residential London street, before moving to the driveway of playwright Alan Bennett where she remained for 15 years (Bennett, 1989). That driveway gave Miss Shepherd a partial respite from the abuse that she suffered while parked on the street, and a 
fixed address that enabled her to obtain social security and other government benefits (Bennett, 1989).

But van living is more often a precarious existence, with challenges related to personal safety, hygiene, and harassment by local residents and the police. Camper van residents may need to move frequently to avoid parking restrictions and attracting attention. And many cities aim to outlaw in-vehicle living through overnight parking bans and anti-camping ordinances (So, MacDonald, Olson, \& Mansell, 2016; Wakin, 2008). Half of cities surveyed by the National Law Center on Homelessness and Poverty had ordinances that restricted living in vehicles, many of them enacted in recent years (NLCHP, 2020). These ordinances might explicitly prohibit using a vehicle as a living accommodation, or take the form of overnight parking restrictions for RVs and other oversized vehicles (NLCHP, 2020; So et al., 2016) such as those illustrated in Figure 2. Enforcement can take the form of fines, but also towing or impoundment of vehicles.

Recently, cities such as Berkeley and Santa Cruz, California have established "safe parking" programs that provide overnight space in off-street parking lots, in conjunction with bans on overnight RV parking on-street (Zeitlin, 2019). But these programs typically provide small numbers of spaces, and an overnight-only program forces residents to move out during the day.
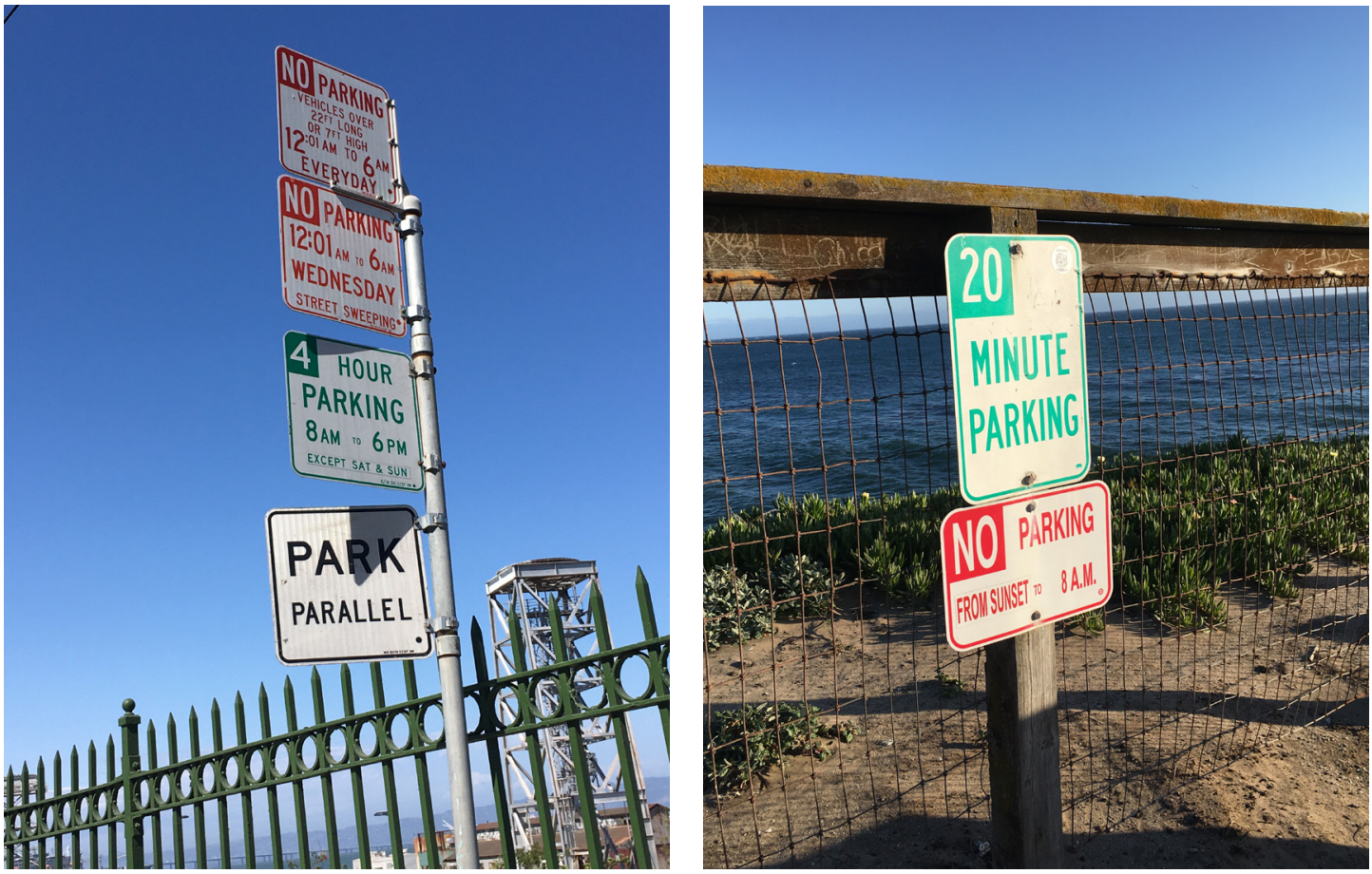

Figure 2. Restrictions on overnight and RV parking

Photos: Author

Why would van residents stay on the streets, rather than move to RV parks or similar places? There are likely many and complex motivations, not least the availability of such sites in urban areas, but cost is undoubtedly a factor. On-street parking on almost all US streets is given away for free, even when adjacent land costs $\$ 10$ million per acre or more. The exceptions to free parking-normally parking meters or residential permits - account for a small fraction of the on-street parking supply, even in dense cities such as San Francisco. Meanwhile, because the marginal value of streets is typically zero, as discussed earlier in this Viewpoint, there is plenty of excess space that can be claimed by camper van residents. Thus, the practice of sleeping in camper vans is a direct reflection not only of a housing crisis, but also the differential pricing of streets and residential land. 


\section{The autonomous camper van problem}

A thought experiment: Picture a not-too-distant future where not only autonomous cars, but also autonomous camper vans, cruise city streets. The camper vans are used by workers who live in more distant cities or the exurbs, allowing them to sleep at home for a few hours and gain extra rest during their commute. But camper vans are also used by some people as a primary residence. Their autonomous camper vans_-or better put, their homes_cruise around at slow speeds, or move from parking space to parking space. Autonomous camper vans become the hallmark of a nomadic element of society.

In this way, autonomous vehicles could circumvent the regulations, such as the anti-camping ordinances noted above, through which cities have targeted van residents. At its simplest, a camper van could simply move frequently enough — perhaps every two to three hours— to evade on-street parking restrictions. At its most complex, a community of camper vans could engage in a coordination game, similar to that analyzed in Millard-Ball (2019). Vans could choose a series of streets on which to descend and come to a self-imposed standstill. Imagine the vans ostensibly attempting to drive around the block, but having their paths mutually obstructed by the other vehicles. Such gridlock would also reduce fuel costs to virtually zero, at least for battery-electric vehicles. By coordinating, explicitly or implicitly, autonomous vehicles could turn in effect travel lanes into parking lanes.

In this scenario, autonomous camper vans might find it cheaper to circle on unpriced city streets rather than pay for parking in an RV park. Because they would not technically be parked, their cruising would be hard for cities to regulate, short of banning non-resident vans altogether from city streets. It is difficult to see how regulations along these lines would not also target commuters, tourists, and roadtrippers who want to drive through the night (as discussed in Cohen \& Hopkins, 2019).

What could a city do in response? One effective and efficient way to stop cruising would be to charge for the use of the street via both time-based and distance-based charges. If a city gives its streets away for free, it is only natural that some nomadically inclined portion of the population would take advantage. But if the price for using streets were to be greater than an off-street alternative (such as an RV park), autonomous camper vans would have little reason to cruise. Since autonomous vehicles can blur the distinction between driving and parking (Millard-Ball, 2019), there is little reason to charge separate amounts for a vehicle to use a parking lane and a driving lane. Rather, cities could charge an hourly fee to occupy the public right of way, in conjunction with a distance-based fee in line with externalities.

In isolation, however, such a pricing strategy would ignore the fundamental issue raised by the autonomous camper van thought experiment - that little land is available for housing, but plenty is available in the form of street rights-of-way. Road pricing might make homelessness less visible but simply price more low-income people away from expensive cities. More broadly, the autonomous camper van problem raises the question: what if streets could be turned into housing through an officially sanctioned process, without the need for autonomous camper vans to cruise? The following section explores some of the possibilities. 


\section{$5 \quad$ Streets into housing}

\subsection{New subdivisions}

In new subdivisions - whether on a greenfield site or redeveloped shopping mall or other brownfieldurban planners have a simple pathway to redressing the economic overprovision of streets. Right-of-way widths could be dramatically reduced as part of the design for a new neighborhood, or left to developers to determine themselves. Indeed, if minimal through traffic is expected, the rationale for government regulation of right-of-way widths is tenuous, as the access, parking, and local movement benefits will all be internalized by the property owners (Millard-Ball, 2021). Even fire access, often the primary rationale for wider streets, can be accomplished with much narrower rights-of-way through using smaller firefighting equipment (Snyder, Siegman, Huff, \& McCormick, 2013), as evidenced in Japan and medieval European cities. In turn, narrower rights-of-way could free up land for more housing.

Certainly, reduced rights-of-way might be a financial windfall for landowners and developers, but there are numerous other public benefits that a city might choose to prioritize. Rather than requiring the developer to effectively hand over a portion of their land via the street, a city could increase inclusionary housing requirements, require an equivalent portion of the land area to be protected as natural habitat, or levy impact fees for contributions to parks and other public services.

But what about existing neighborhoods? Here, a practical path towards turning streets into housing is more complex. The following subsections chart out potential strategies for the short and long term.

\subsection{Streets as canals}

The simplest way to turn streets into housing is to do nothing, and allow camper van residents and others living in vehicles to use surplus space on the rights-of-way for long-term parking. Indeed, many cities already pursue a variant of this strategy by lightly enforcing overnight parking restrictions or turning a blind eye to violations, especially in non-residential neighborhoods.

Such a "tolerance only" strategy is unlikely to be ideal for van residents. It gives them little in the way of security of tenure, especially if they can be moved on by the police or towed at any time. It gives residents no access to essential services-water, electricity, and sewer hookups, trash collection, mail delivery, and bathrooms for car and minivan campers. And the constant churn of residents may make it hard for communities to develop and enforce norms around noise, dogs, cleanup, and related issues.

These problems might be overcome through providing services and formalizing the rights of camper van dwellers to street space. Indeed, there is already a precedent for converting redundant transportation infrastructure into housing: canal boat dwellers in high-rent British cities such as Oxford and London, where liveaboards provide a relatively low-cost source of additional housing. In the UK, an estimated 15,000 people live on boats - some drawn by the lifestyle and some for reasons of affordability (Davison, 2019). While some are "continuous cruisers" subject to time limits (often two days or two weeks) in a particular place, others lease long-term residential moorings. In Oxford, the local plan sets out criteria for when new moorings will be approved, such as ecological, access, and safety considerations and the availability of services such as sewage and rubbish disposal; the city even commissioned an assessment of boat-dweller needs (RRR Consultancy, 2018).

In a similar way to canal boat living, local governments could formalize camper van living, allowing vehicle owners to rent part of the street on a short- or long-term basis, and providing sanitation, water, electricity and other basic services. The rental fee could be nominal, but would provide more certainty to households that they would not be moved on or towed by law enforcement. Figure 3 develops this analogy. 

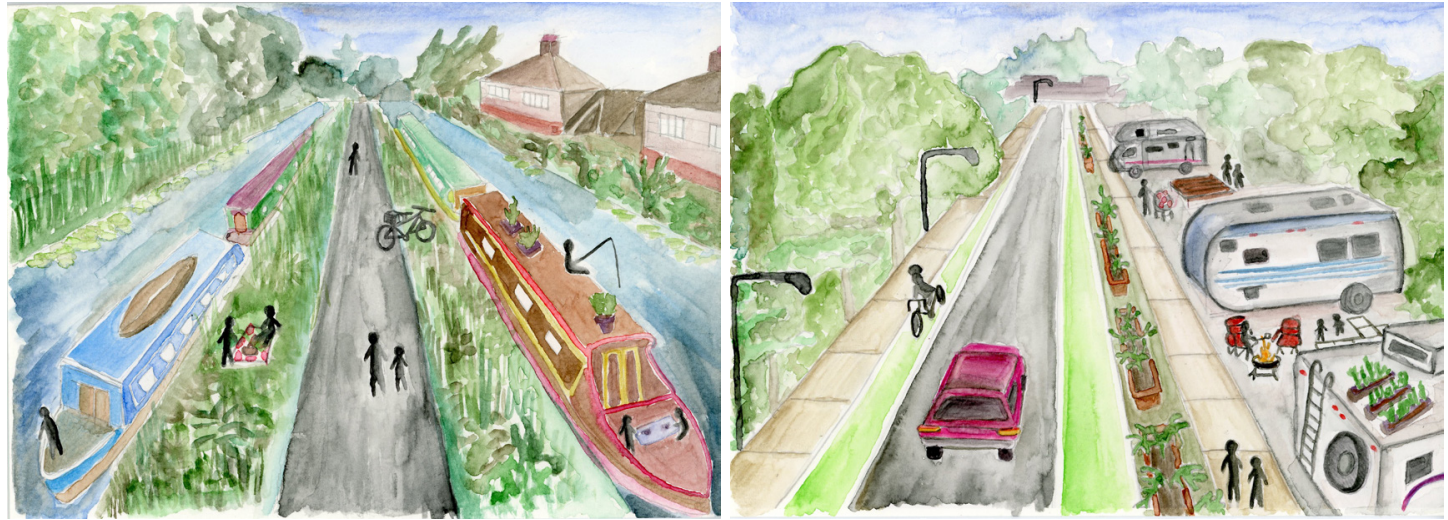

Figure 3. Camper van living and the canal boat analogy

Cities already repurpose redundant transportation infrastructure for canal boat living (left panel). Residents pay lease fees in exchange for security of tenure and basic services. The same concept could be applied to camper vans (right panel). In contrast to existing informal practices, residents would lease a space and have access to services such as water and electricity.

Art: Erin Single

The accommodations need not even be a van; mobile tiny houses could do the same, with a yearlong lease agreement making the transportation and set-up costs worthwhile for residents. A tiny house community might be particularly appropriate on streets with medians, if one side can provide the transportation function and the other side be devoted to housing. Small-scale tiny home villages for homeless people have been built in places such as Denver, Colorado, and using excess street rights-of-way might help the concept expand further through avoiding the challenge of finding surplus lots that could accommodate tiny homes. As Alexander (2019) notes, such tiny home communities can build social capital as well as provide low-cost housing, with stewardship agreements providing a mechanism for self-governance and the upkeep of common areas.

Van living or on-street tiny houses might not meet the needs of everyone currently living on the street, many of whom have mental health or substance use challenges that necessitate a higher level of support. But such a strategy would expand the supply of low-cost housing and cater to a wider constituency of people experiencing housing precarity.

Of course, housing is only one of the potential alternative uses for street rights-of-way. Cities increasingly devote street rights-of-way to outdoor dining, a practice that has accelerated since the advent of the covid-19 pandemic. Even before covid, parklets (sidewalk extensions into the parking lane, often to provide outdoor seating for restaurants and other adjacent businesses) were becoming commonplace in cities. With little fanfare, cities also permit food trucks to park on the street and close off entire blocks to cars for farmers markets. All these actions are a tacit recognition that there are more productive uses for the street right-of-way than the movement and storage of vehicles. And if these more productive uses include sipping a cappuccino al fresco, why not a more fundamental human need-housing — as well?

\subsection{Moving the lot boundaries}

A camper van community would, to put it mildly, be unlikely to be welcomed with open arms by most residents on the streets where they live. Local opposition to even modest infill development is well documented, and an influx of people living in vehicles would probably generate even more fear and pushback. Thus, non-residential neighborhoods might be the best prospects for formalizing camper van and on-street tiny house communities. 
But what of the large reservoir of excess right-of-way on suburban, residential streets? Here, gaining the support of neighborhood residents may rely on aligning their incentives with an increase in housing supply. In other words, allowing homeowners to gain from building additional floorspace or accessory units on their own lots may at least soften opposition to neighborhood change.

An immediate and straightforward option would be to allow camper vans parked on a home's driveway to serve as a form of accessory dwelling unit. Electricity, water, bathroom access, and other services would become the responsibility of the homeowner. Cars that formerly parked on the driveway, in turn, could shift to on-street spaces on the public right-of-way, where ample capacity is normally available in suburban neighborhoods.

A more far-reaching option would be to expand residential lots into the street right-of-way, in order to create space for an accessory dwelling unit in the front setback. Thigpen and Volker (2017) detail a similar proposal. Many possible configurations are possible and several are illustrated in Figure 4: a freestanding unit, a garage conversion or expansion, or an extension to the main house that creates space for a separate unit.

The new unit need not physically extend into the former right-of-way. Indeed, doing so might create complications if a city wishes to preserve the option of a wider street in the future, or where water, sewerage, and other utilities are routed under the sidewalk. In such instances, a city could simply eliminate front setback requirements, allowing property owners to build to their front lot line. The functions of the setback in providing privacy and a buffer could then be performed by greening the street itself, through planting trees and reducing impervious surfaces. Figure 4 shows an example.

In short, the possibilities to convert street rights-of-way into additional housing and other productive uses are only limited by the creativity of urban designers. Even if only some properties on a block expand into the former street right-of-way, the remnant spaces could be used for planted areas, play structures, or other design improvements. Streets do not need to be continuously aligned (Guo \& Schloeter, 2013), and indeed an irregular right of way can create benefits in terms of slowing down traffic.

The adjustment of lot lines in conjunction with new construction has much precedent, if in the opposite direction. Cities often require building setbacks to accommodate street widening or an additional turn lane, particularly if a larger or more intensive use is proposed on a site. Such setbacks can lead to an irregular pattern where the street widens out at intervals before narrowing again, as documented in Los Angeles by Manville (2017). Court cases in Detroit, Pittsburgh, Kansas City, and elsewhere have long upheld the right of cities to require a property owner to cede land to streets as a condition of redevelopment (American Society of Planning Officials, 1949; Randall, 1929).

If lot lines can be adjusted inwards where a street is considered too narrow, why not outwards where a street is too wide? Cities could sell their excess right-of-way to a developer in conjunction with a new construction project, or cede it in exchange for more affordable housing units or other community benefits. 

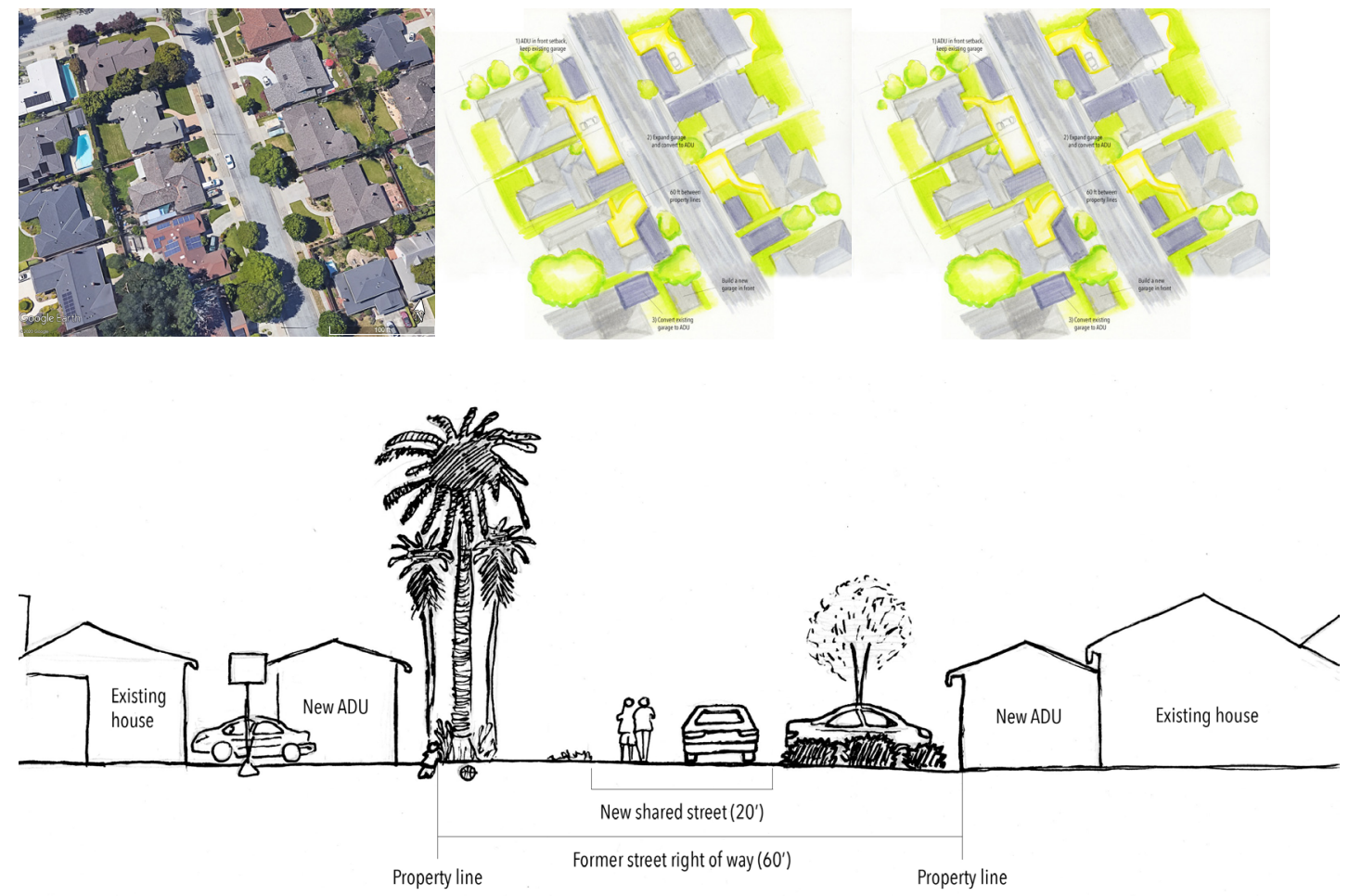

Figure 4. Prototypical street narrowing to allow for housing

The prototype is based on a residential street with a 60-foot right-of-way and minimal through traffic, located in a single-family home neighborhood about six miles south of downtown San Jose, CA. The left panel shows the existing conditions. In the center panel, accessory dwelling units (ADUs) are constructed in front setbacks, either as free-standing units or as expansions of existing garages. In the right panel, the sidewalk is removed and the street is narrowed, creating space for landscaping that replicates the functions of the front setbacks. Perpendicular parking is provided at intervals. A 20-foot wide shared street accommodates pedestrian and vehicle travel. The lower panel provides the cross-section illustrated in the right panel.

Art: Erin Single

\section{Conclusions}

In US cities today, far too much land is devoted to the street right-of-way. Urban designers have increasingly challenged the width of lanes and streets, and called for road diets and other design interventions that convert car lanes into space for bicycles, stormwater management, or play space (Hebbert, 2005; NACTO, 2013). But in general, designers have worked within the framework of a fixed right-of-way width rather than challenging the overall amount of urban land that is devoted to streets. Even scenarios for autonomous vehicles have largely sought to repurpose rather than slim down the rights-of-way (NACTO, 2019; Riggs, Schlossberg, Shay, \& Millard-Ball, 2019).

In cities where land is cheap and plentiful, there is little opportunity cost to wide rights-of-way. But in high-cost housing markets such as coastal California, land availability is a key constraint on housing production. In turn, one of the fundamental causes of homelessness in these places is the high cost of urban housing and the scarcity of housing options for low- and moderate-income people. In reality, the shortage of land is in large part an artefact of zoning restrictions, fees, slow-walking of permits, and related practices that constitute the "regulatory hydra" (Monkkonen, Lens, \& Manville, 2020; Monkkonen \& Manville, 2020). But it is also an artefact of street restrictions, or more specifically subdivision 
ordinances that mandate rights-of-way of 50 feet or even more.

The more that housing costs rise-in part due to overly wide streets— the more people turn to live on those same streets, often in cars or camper vans. Despite the efforts of many cities to thwart the practice through anti-camping ordinances and parking restrictions, people are already turning streets into housing. On an informal basis, living in a camper van can be precarious. But if cities recognize that the practice stems from a fundamental distortion in the use of urban land, they could move beyond a view of housing affordability as an issue for the portion of the city that is "not street" (e.g., residential land), and consider the potential contribution from the $15 \%$ to $30 \%$ of a city that is devoted to street rights-of-way.

Such a transformation can begin through formalizing camper van living in the same way as cities have done with liveaboard canal boats; through reducing the widths required in new subdivisions; and through reducing or eliminating the street widenings required as a condition of redevelopment of a site. In the longer term, cities can begin to cede their excess rights of way to adjacent property owners in order to permit accessory dwelling units or redevelopment at higher densities. In short, more people should be living on the streets, albeit in a more formalized and supportive manner.

The consequences of overprovision of streets are evident today: street space is underutilized and unpriced, while residential and commercial rents and sale prices make many metropolitan regions increasingly unaffordable. A future with autonomous camper vans may bring the misallocation of urban land into sharper relief. If streets are too wide today, they will be even further from their optimal width in an era of autonomous vehicles which can park remotely and navigate much narrower lanes. Moreover, autonomous camper vans are better placed to evade regulatory constraints such as overnight parking bans and take advantage of the land - streets - that cities mostly give away for free. The prospect of endlessly cruising vans brings into view the overprovision and underpricing of streets. Just as importantly, it illustrates how street design manuals ignore the simple economic prescription that the more valuable the urban land, the narrower a street should be.

Autonomous vehicles provide an important thought experiment: what if land were more fungible, rather than strictly allocated into buckets of "vehicle travel," "parking," "housing," and so on? If cities already had the optimum balance between land for streets and land for housing and priced that land in a consistent way, there would be little gap for arbitrage. But in cities such as San Jose, raw land dedicated for "housing" sells for $\$ 2$ million or more per acre, while adjacent land dedicated for "roads" is both underutilized and given away for free. Rather than seeking to regulate to prevent unhoused people from occupying that land, cities might think more deeply about municipal reforms can begin to turn streets into housing.

\section{Acknowledgements}

I am indebted to Ralph Torrie for first bringing my attention to the specter of autonomous camper vans and for comments on an early draft, and to Erin Single for developing the imagery. I appreciate comments from C. J. Gabbe, Matthew Thompson, Robin Levitt, and seminar participants at the Institute for Social Transformation at UC Santa Cruz.

This study was made possible through funding received from the Norris Center at UC Santa Cruz, and by the University of California Institute of Transportation Studies Statewide Transportation Research Program funded by the Road Repair and Accountability Act of 2017 (SB 1). I would like to thank the State of California for its support of university-based research, and especially for the funding provided in support of this project. 


\section{References}

Alexander, L. T. (2019). Community in property: Lessons from tiny homes villages. Minnesota Law Review, 104(1), 385-464.

All Home. (2020). Seattle/King County point-in-time count of individuals experiencing homelessness. Retrieved from https://regionalhomelesssystem.org/king-county-point-in-time-count/

American Society of Planning Officials. (1949). Building lines, mapped streets, setbacks, front yards (information report 1). Chicago: American Society of Planning Officials.

Angel, S., Lamson-Hall, P., Madrid, M., Blei, A. M., Parent, J., Galarza Sánchez, N., \& Thom, K. (2016). Atlas of urban expansion (Vol. 2: Blocks and roads). New York: NYU Urban Expansion Program and Lincoln Institute of Land Policy. Retrieved from http://www.atlasofurbanexpansion.org

Been, V., Ellen, I. G., \& O’Regan, K. (2019). Supply skepticism: Housing supply and affordability. Housing Policy Debate, 29(1), 25-40. https://doi.org/10.1080/10511482.2018.1476899

Bennett, A. (1989). The lady in the van. London Review of Books, October 26. Retrieved from https:// www.lrb.co.uk/the-paper/v1 1/n20/alan-bennett/the-lady-in-the-van

Cohen, S. A., \& Hopkins, D. (2019). Autonomous vehicles and the future of urban tourism. Annals of Tourism Research, 74, 33-42. https://doi.org/10.1016/j.annals.2018.10.009

Davis, M., Larson, W., Oliner, S., \& Shui, J. (2020). The price of residential land for counties, ZIP codes, and census tracts in the United States (working paper 19-01). Washington, DC: Federal Housing Finance Agency. https://www.fhfa.gov/PolicyProgramsResearch/Research/Pages/wp1901.aspx

Davison, N. (2019). The lure of life on a London boat. The Financial Times, March 29. Retrieved from https://www.ft.com/content/34e44cd6-304e-11e9-80d2-7b637a9e1ba1

Dinkelspiel, F. (2019). Number of people living in cars, RVs and tents increases in Berkeley. Berkeleyside, September 12. Retrieved from https://www.berkeleyside.com/2019/09/12/number-of-peopleliving-in-cars-rvs-and-tents-increases-in-berkeley

Gabbe, C. J., Pierce, G., \& Clowers, G. (2020). How much do regulations matter? The effects of residential minimum parking requirements in Seattle. Land Use Policy, 91, 104053. https://doi. org/10.1016/j.landusepol.2019.104053

Glaeser, E., \& Gyourko, J. (2018). The economic implications of housing supply. Journal of Economic Perspectives, 32(1), 3-30. https://doi.org/10.1257/jep.32.1.3

Guo, Z., \& Schloeter, L. (2013). Street standards as parking policy: Rethinking the provision of residential street parking in American suburbs. Journal of Planning Education and Research, 33(4), 456-470. https://doi.org/10.1177/0739456X13504299

Hebbert, M. (2005). Engineering, urbanism and the struggle for street design. Journal of Urban Design, 10(1), 39-59. https://doi.org/10.1080/13574800500062361

Ho, V. (2019). The Californians forced to live in cars and RVs. The Guardian, August 5. Retrieved from https://www.theguardian.com/us-news/2019/aug/05/california-housing-homeless-rv-cars-bay-area

HUD. (2020). The 2019 annual homeless assessment report (AHAR) to Congress. Washington, DC: U.S. Department of Housing and Urban Development. https://www.huduser.gov/portal/datasets/ ahar/2019-ahar-part-1-pit-estimates-of-homelessness-in-the-us.html

Lin, D., \& Wachter, S. (2020). Land use regulation, regulatory spillover and housing prices. Retrieved from http://dx.doi.org/10.2139/ssrn.3363947

Manville, M. (2017). Automatic street widening: Evidence from a highway dedication law. Journal of Transport and Land Use, 10(1), 375-393. https://doi.org/10.5198/jtlu.2016.834

Manville, M., \& Shoup, D. (2005). Parking, people, and cities. Journal of Urban Planning and Development, 131(4), 233-245. https://ascelibrary.org/doi/10.1061/\%28ASCE\%2907339488\%282005\%29131\%3A4\%28233\%29 
Meyer, J. R., \& Gómez-Ibáńez, J. A. (1981). Autos, transit, and cities. Cambridge, MA: Harvard University Press.

Millard-Ball, A. (2019). The autonomous vehicle parking problem. Transport Policy, 75, 99-108. https:// doi.org/10.1016/j.tranpol.2019.01.003

Millard-Ball, A. (2021). The width and value of residential streets. Journal of the American Planning Association. https://doi.org/10.1080/01944363.2021.1903973

Monkkonen, P., Lens, M., \& Manville, M. (2020). Built-out cities? How California cities restrict housing production through prohibition and process. Berkeley, CA: Terner Center for Housing Innovation. Retrieved from http://californialanduse.org/download/MLM\%20Built-Out\%20Cities\%202020.pdf

Monkkonen, P., \& Manville, M. (2020). Planning knowledge and the regulatory hydra. Journal of the American Planning Association, 86(2), 268-269. https://doi.org/10.1080/01944363.2020.1725255

NACTO. (2013). Urban street design guide. Washington, DC: Island Press/National Association of City Transportation Officials. http://nacto.org/publication/urban-street-design-guide/

NACTO. (2019). Blueprint for autonomous urbanism (2nd edition). Washington, DC: National Association of City Transportation Officials. Retrieved from https://nacto.org/publication/bau2/

NLCHP. (2020). Housing not handcuffs 2019. Ending the criminalization of homelessness in U.S. cities. Washington, DC: National Law Center on Homelessness and Poverty. Retrieved from http://nlchp.org/wp-content/uploads/2019/12/HOUSING-NOT-HANDCUFFS-2019-FINAL.pdf

Norton, P. D. (2008). Fighting traffic: The dawn of the motor age in the American city. Cambridge, MA: MIT Press.

Quigley, J. M., \& Raphael, S. (2001). The economics of homelessness: The evidence from North America. European Journal of Housing Policy, 1(3), 323-336. https://doi.org/10.1080/14616710110091525

Randall, C. E. (1929). Validity of the use of setback lines for street widening. Marquette Law Review, 13(2), 103-110.

Riggs, W., Schlossberg, M., Shay, E., \& Millard-Ball, A. (2019). Transforming street design: Approaches to reengineering our neighborhood streets. In W. Riggs (Ed.), Disruptive transport. Driverless cars, transport innovation and the sustainable city of tomorrow (pp. 51-65). Oxfordshire, UK: Routledge.

RRR Consultancy. (2018). Oxford boat dwellers accommodation needs assessment (Final report, report to Oxford City Council). Gainsborough, UK: RRR Consultancy. Retrieved from https://www.oxford.gov.uk/downloads/file/5133/oxford_boat_dwellers_accommodation_needs_ assessment

Snyder, R., Siegman, P., Huff, H., \& McCormick, C. (2013). Best practices. Emergency access in healthy streets. Los Angeles: Los Angeles County Department of Public Health. Retrieved from https://nacto.org/wp-content/uploads/2015/04/Best-Practices-Emergency-Access-in-Healthy-Streets.pdf

So, J., MacDonald, S., Olson, J., \& Mansell, R. (2016). Living at the intersection: Laws \& vehicle residency. Seattle: Seattle University School of Law, Homeless Rights Advocacy Project. Retrieved from https://papers.ssrn.com/sol3/papers.cfm?abstract_id=2776423

Thigpen, C. G., \& Volker, J. M. B. (2017). Repurposing the paving: The case of surplus residential parking in Davis, CA. Cities, 70, 111-121. https://doi.org/10.1016/j.cities.2017.06.020

Wakin, M. (2008). Using vehicles to challenge anti-sleeping ordinances. City \& Community, 7(4), 309329. https://doi.org/10.1111/j.1540-6040.2008.00269.x

Wakin, M. (2014). Otherwise homeless: Vehicle living and the culture of homelessness. Boulder, CO: First Forum Press.

Wehman-Brown, G. (2016). Home is where you park it: Place-making practices of car dwelling in the United States. Space and Culture, 19(3), 251-259. https://doi.org/10.1177/1206331215596489

Zeitlin, M. (2019). Affordable housing is disappearing. So cities are designating parking lots to sleep in. Vox, October 18. Retrieved from https:/www.vox.com/the-highlight/2019/10/11/20897485/ california-homeless-safe-parking-lots-cars-rvs 